\title{
Digital economy: backgrounds, main drivers and new challenges ${ }^{\mathrm{a}}$
}

\author{
Askar Akaev ${ }^{1}$, Askar Sarygulov ${ }^{2 *}$, and Valentin Sokolov ${ }^{2}$ \\ ${ }^{1}$ Moscow State University, 119991 Leninskie Gory 1, Russian Federation \\ ${ }^{2}$ Saint Petersburg State University of Economics, 191023 Sadovaya st. 21, Russian Federation
}

\begin{abstract}
The industry development over the last hundred years has had a huge impact on the development of technological infrastructure and life change. Three main components of this development are related to personalization: a car as a personal vehicle and greater personal freedom; a personal computer as a means of intellectual autonomy; a personal phone as a means of freedom of communication and access to information. These three development factors significantly changed the employee psychology and created the conditions for diffusion of qualitatively new, synthesized (cyber-physical) technologies that became the basis of the Industry 4.0 and the Internet of Things - two main working concepts of industrial and infrastructural development for the next 20 years. The conventional or classical industrial systems that are dominant to the present day have mainly been based on the principles of human muscle energy replacement, but the technological changes of our days raise the question of the substantial scale of displacement of the living manpower both in production and in management and services. The process of technological and industrial transformation that has already begun will inevitably lead to the transformation of social and economic systems, and here the key problem will not only be the provision of a new quality of economic growth, but also the solution of the employment problem interfacing a new technological platform, the information and social infrastructure of society.
\end{abstract}

Significant efforts made by financial regulators to overcome the consequences of the 20082009 crisis did not lead to a noticeable revival of the economy of the industrialized countries. As applied to the US economy, this phenomenon was characterized as "secular stagnation" [1]. Researchers who analyzed more than 10-year stagnation in the Japanese economy, as a reason, indicated the low efficiency of capital use [2-3]. The same process was called "stagnation traps" [4], when under pessimistic expectations, a gap between large volumes of production and low growth rates can coexist.Japanese and Korean economists in their joint study see the reason for the Japanese economy stagnation at an extremely low rate of capital expenditure connected with its development [5].

\footnotetext{
${ }^{a}$ This article was prepared under financial support of the Russian Science Foundation (Grant No. 1818-00099)

*Corresponding author:cfr@engec.ru
} 
The most recent crisis (2007-2009) was predetermined not only by the presence of "bubbles" in the sphere of finance, but also by the allometric character of the sectoral development, when disproportionately high shares in national economies fell on one sector (finance, services), while the share of other industries first of all processing) catastrophically reduced. This structural imbalance accumulated over the years was the result of non-conjugation of a new technological platform, control forms and methods, and practices of social development.

All this predetermined two options for solving the accumulated problems: widespread use of economic policy methods to overcome the stagnation is aggregate demand stimulation, the policy of low interest rate and new investments support in the economy, and a number of other regulatory measures. In addition, another way has been outlined to solve the problem of economic stagnation: search for new technological solutions that could qualitatively change the entire economic landscape and give a new impulse to development. Here, it is necessary to note the recommendations for the development strategy "The Industry 4.0" for German manufacturers [6], two American concepts: "The Industrial Internet" [7] and "The Internet of Things" [8]. The paper on artificial intelligence [9] published in 2003 laid the foundations for the industrial development of the systems with artificial intelligence. At the World Economic Forum 2016, K. Schwab initiated a broad discussion on the Fourth Industrial Revolution [10]. The well-known book [11] assesses the positive consequences of the use of digital technologies primarily in the form of increase in performance and provision of more creative character of employees' compensation. Other researchers warn of the potentially high risk of new industrial systems, firstly, in the area of economic inequality [12]. In general, the world industry and services sector are accumulating the necessary "critical mass" of new knowledge and technologies, which can create new conditions for development like an explosion. And consumption personalization and social demands individualization can be considered as a point of transition to a new machine era which includes: a) the Industry 4.0; b) the Internet of Things; c) AI elements based systems.

These qualitative changes have matured over the past 25-30 years - a period that can be characterized as a zigzag of history and economic divergence. A key feature of world development in this period was the slowdown in economic growth in industrialized countries at simultaneous social and economic polarization. The actual locomotives of the world economy were rapidly growing China and India. Another important feature was the qualitatively new role of information and communication technologies which became the basis of a new digital infrastructure of society. The analysis of the structural dynamics of the world's developed countries shows that a set of conditions (information-technological, managerial-organizational, financial, consumer) is maturing in them, the combined effect of which provides a qualitatively new trend of economic development. In our view, a long stagnation period, especially in the industrial development of the world's leading economies (G-7 countries), which covers the last 20 years, is largely due to the structural unpreparedness of their economic and industrial systems to a qualitatively new stage of development. Our previous analysis of the manufacturing industry structure in terms of technologies and employment structure of the G-7 countries showed that there is a decrease in the employment rate in the industry and the manpower flow to the service sector for 1980-2010 and practical invariance of industry sectors rate in terms of the technologies level for the same period. [13] With regard to changes in the labor nature, they are characterized by three main trends: a) direct substitution of human functions based on robotic and computer application; b) rapid depletion of certain types of professions due to the availability of global information and social networks; c) rapid growth of the parallel labor market. Therefore, the key question is how to ensure the development of those types of technologies which will continue to provide human participation in the production 
process, without making it an "appendage" of new intellectual systems. This problem solution will reduce the risk of increasing inequality and financial instability.

The technological breakthrough taking place presently has not arisen without reason. It was preceded by the stage of a rather long period of decrease in growth rates and significant reduction in the share of industry in the GDP of all industrialized countries. However in the depths of these processes, new scientific ideas matured and applied research was carried out which were later materialized in several key lines.

The first line was directly related to the development of the technologies themselves in the field of new materials and methods for their obtaining. Here it is necessary to identify nanotechnologies that significantly extended the potential for obtaining new materials with predefined properties and technology of layered synthesis (3D printing).

The second line is based on the development of data processing technologies (BigData, cloud computing, augmented reality, neural systems) and exploratory studies on the creation of quantum computers, new generation supercomputers.

The third line is to find a synergistic effect from the convergent nature of the use of advanced technologies and new knowledge which led to the creation of not only new (NBIC) technologies, but also gave wide opportunities for the development of the life science, human genome research, creation of a new generation of medicines and prolongation of human life.

The fourth line focuses on the studies for creation and operation of industrial systems with the artificial intelligence elements and global digital infrastructure that allows practical tasks such as the creation of "smart factories", "smart cities", "digital currencies" or robotic cars. In the most concentrated form, this was reflected in the following concepts: "Digital Economy" (2001), "Crypto-Currency" and "Blockchain" (2008), "Industrial Internet" (2012), "Internet of Things" (2012), "Industry 4.0" (2013), "Second Machine Age" (2014) and "The Fourth Industrial Revolution" (2016).

The next line is related to the commercialization of those technological solutions that fundamental and applied science transferred to the industry. A special feature of this process was the qualitatively new role of outsourcing when new diagrams of production cooperation led to a wide diffusion of technologies and a sharp decrease in costs. The consequence of all this was the emergence of broad capabilities and relatively inexpensive technical gadgets. Their accessibility and availability of global information networks have opened new opportunities for both the consumer and business.

A separate line was studies on the impact of new technologies on the level of employment and the processes of economic inequality. The dominant characteristic of studies in this line is the formulation of the problem itself and recognition of the need for deep institutional and legal reforms.

The next line of research is connected with the formation of a parallel labor market under new opportunities provided by electronic platforms. New opportunities for selforganization of labor activity have a significant impact on the character of mutual relations between the manufacturer of goods and services and the consumer, since they often change roles and erase previously existing tight bounds in the conventional diagrams: "manufacturer-seller-consumer".

Modern trends in industrial development are largely based on the digital technologies. In this regard, it is not unexpected that there is a question on the stability of this trend. Especially in the context of the relatively recent (2000-2001) crisis in IT companies, when the market capitalization of the Internet and telecommunications companies fell by 1.775 trillion dollars and led to a massive bankruptcy of about 300 large companies [14]. It should be noted that among these companies there were not only Internet providers, but also engaged in e-commerce (Cyberian Outpost, eToys.com, Pets.com, Webvan), social networking (theGlobe.com), digital currency trading (Floos .com), online video and audio 
hosting (Pixelon, Ritmoteca.com). Such high-tech companies as Cisco, Qualcomm, eBay, Amazon.com, Google emerged the crisis with significant losses. The crisis cause laid not only in the context of broad market speculation in the shares of IT companies, but also in the unreasonably high expectations of investors and consumers from the sphere of IT services, the absence of developed digital infrastructure, powerful and capable of on-line data retrieval systems oriented tomass consumer. As well as there were no high-tech and affordable gadgets that significantly reduced the field of new technologies application. Now, almost 15 years later, this technological gap has been overcome. The practice of industrial development and management in recent 5-10 years demonstrates the specific examples of technological breakthroughs: creation of robotic cars (Google, Tesla), voice recognition technologies (Siri, Alexa), a new generation of storage robots (Amazon Kiva), exponential growth of microchip density, data load and process rate, capacity of data warehouses and their energy efficiency. Rapid development of the Internet and the associated growth in e-commerce led to the creation of new technologies for bank transactions - blockchain. This allowed reducing the terms for the funds transfer from 5-6 banking days to 20 seconds [15]. The growth of digital technologies, social networks and smart phones has contributed to faster and more targeted customer satisfaction, creation of new companies (Uber, Amazon, Alibaba, Facebook, Netflix, iTunes) and bankruptcy of others (for example, Borders, Blockbuster, Kodak, as a result of which 250 thousand people in total lost their jobs). Rapid growth rates of a number of different robots and systems with artificial intelligence (AI) shall be specially mentioned. On the one hand, global investments in start-ups related to AI development have reached their five-year peak in 2016 and amounted to 5.02 billion dollars [16]. On the other hand, the US practice for development of high-tech industries has showed that only $8.8 \%$ of manpower in the $1980 \mathrm{~s}$, $4.4 \%$ in the 1990 s and only $0.5 \%$ in the 2000 s have transferred to these sectors [17]. The banking sector susceptible to innovation has already announced future large-scale staff reductions: the American CitiBank will reduce 30\% of employees until 2025; three largest Japanese banks (Mizuho Financial Group Inc, Sumitomo Mitsui Financial Group Inc and Mitsubishi UFJ Financial Group Inc) for the same period will reduce 33 thousand employees. The American researchers consider that it quite possible that almost $47 \%$ of workplaces are under direct threat of automation and substitution by robots, software products or artificial intelligence [18], for Germany, this figure is even higher - up to 59\% [19], and, for countries of Southern Europe, it varies from 45 to 60 percent [20]. The specialists from MIT assess that in the near future one robot will substitute 3.2 to 5.4 workers [21]. It should be noted that robots are increasingly used not only in industry, but also in services and households. So, according to the International Federation of Robotics, $2.6 \mathrm{mln}$. industrial robots and $42 \mathrm{mln}$. services and households robots will be used in the world in 2019. Thus, technological transformation will inevitably lead to the transformation of social and economic systems.

The conventional or classical industrial systems that are dominant to the present day have mainly been based on the principles of human muscle energy replacement (steam force, internal combustion engine, electricity). Intellectual abilities were fully used and their replacement with machines in the course of production, management or design was minimal. However, the technological changes of our days raise the question of the substantial scale of displacement of the living manpower both in production and in management and services. And this cardinally changes the entire economic and social landscape.

Another important component lies in the plane of the forms of organization and conduct of business. The system existence for years a priori proceeded from the fact that people shall be organized into certain structures with internal rules and their hierarchy, and the results of their activities shall be mediated by a multitude of agents before they reach the 
end user. This inevitably caused complex systems of production, supply, storage, sale, trade and imposed certain mutual obligations on both parties in case of hiring and firing. Actual technologies offer ample opportunities for self-employment that already leads to the creation of a parallel labor market, blurring the line between the concepts "work" and "home". The latter circumstance raises the question of reviewing many regulatory standards in the field of employment, taxation, medical insurance and pension coverage. For example, in the EU countries, almost $55 \%$ of self-employed people $(13 \%$ of the overall number of labor force) are at risk of losing unemployment benefits and $37.5 \%$ are at risk of losing sick benefits [22]. Modern giants of the digital industry (Google, Amazon, Twitter) actively use information generated by network users for commercial purposes. This process is called "Digital Taylorism" or "Crowd sourcing". Many researchers consider these processes as extremely negative, but their comprehensive and systematic study has not yet been made.

New technologies also provide ample opportunities for rapid and direct economic exchange of goods and services between the manufacturer and the end user, often separated by thousands of kilometers. And this forms a new type of relationship, without intermediaries, with a high level of individualization of the request and the targeting and accuracy of its satisfaction by the manufacturer. In classical economic systems there was a close-out separation of labor into living and materialized, the latter has a purely production, but not a creative nature. Modern complex software products (it is not yet artificial intelligence) are able to replace a person, for example, in the analysis of standard banking transactions or stock trading on the stock exchange or, as Uber's experience shows - to replace entire companies. While carrying out such functions, embodied labor already changes its character and is capable of variability and generation of new added value. More complex systems, for example oriented to pattern recognition are able to control technical means (for example, cars) and in this case, the scale of replacement of living labor already look frighten. All of these raise the question of the nature of capital accumulation, since new intellectual systems with a high capitalized value can potentially create conditions for the dominance of machines over man, not only in the sphere of production, but also in the sphere of services and social communication.

Many processes in the economy acquire a qualitatively new character due to the trunk nature of digital technologies, which:

- Constantly expand the range of economic activities, creating conditions for the growth of return on capital at practically zero marginal costs;

- Promote the emergence of new business models based on the market competition of digital goods and services;

- Offer ample opportunities for the network principle of production organization, actually blurring the lines between manufacturers, sellers and consumers;

- Create an unprecedented amount of data and at the same time provide various tools for processing and using this resource that transforms data numerically into a strategic resource and makes it one of the main organizational principles of both the economy and society as a whole.

In June 2015 MIT Technology Review published the Open Letter on Digital Economy, initiated by an international group of scientists and representatives of private companies. During the wide discussion of this letter, a future program of action and research emerged, which can be divided into three major areas:

- Changes in government policies in education, infrastructure, entrepreneurship, trade, immigration, research and other key areas that will help create jobs and improve the economy.

- Business and organizational models that will help to achieve not only higher productivity and profit for companies, but also greater prosperity for their managers, investors, workers and society as a whole. 
- Study of the economic and social consequences of the digital revolution, so that innovative and long-term solutions can be adopted.

Several centers have been created by now, that study various aspects related to the formation of the economy based on a new technological platform.

The Massachusetts Institute of Technology (MIT) performs extensive studies in the field of assessing the impact of workplace automation and robots application [20]; the same questions are in the purview of scientists at the Boston Columbia University [22].

The University of Oxford [18] conducted extensive studies and assessed the probabilities of full computerization of many professions with respect to the American economy. The University of Oxford together with Citibank (Citi Global Perspectives \& Solutions) in 2016 published the results of extensive studies on the state of the economy of key countries and the problems of transition to a digital economy (Technology at Work v2.0).

The problems of technological development, jobs future, inequality and productivity are constantly monitored by the McKinsey Global Institute (MGI) and are reflected in a number of scientific reports [24-27].

The European Trade Union Institute focuses on studies of employment issues, new forms of business organization, performance of institutional reforms and protection of workers' interests. This was reflected in two working documents of the Institute for 2016 [28-29].

The problems of economic inequality are studied under the auspices of the Washington Center for Equitable Growth. Here, first of all, it is necessary to mention the following papers: E. Jacobs [30] and C. M. Mody [31].

The platform of the World Economic Forum initiated two important reports on the possibilities and consequences of the new industrial revolution [32-33].

The issues of economic and technological challenges are conventionally in the purview of major international organizations: Organization for Economic Co-operation and Development (OECD) that with an interruption of 16 years published two reports having the direct relation to the problems of the digital economy [34-35]. The same issues are monitored by the United Nations Industrial Development Organization (UNIDO) which were reflected in the document for 2016 [36-37].

Among the European countries it is necessary to allocate Germany that not only proposed in 2013 the concept of "The Industry 4.0" prepared by the representatives of the Federal Government, academic and business groups, but also the Action Program to provide a smooth transition to a new type of economy that was reflected in the document of the Federal Ministry of Labor and Social Affairs [38].

As for the Russian research segment, it should be noted the following:

- The program "Digital Economy of the Russian Federation" [39] adopted in 2017;

- Survey report "Digital Economy: Global Trends and Practice of Russian Business" prepared by the HSE Institute of Innovation Management (HSE IIM) [40];

- The results of joint comprehensive studies on the problems of "Industry 4.0" performed by Russian and foreign scientists and published in a separate monograph in the Publishing House "Springer Verlag" in 2017 [41].

The non-profit, private found Ewing Marion Kauffman Foundation (USA) opened an on-line platform for an open discussion on the problems of development and support of entrepreneurship and innovation under new technological challenges, and invited the representatives of academic and business circles to participate.

The analysis of the most recent publications and literary sources, as well as trends in production shows that new conditions have practically been created that can provide the structural transformation of industrial and economic systems since: 
- a digital infrastructure has been formed that includes the public Internet and a set of technically simple gadgets, social networks, systems for on-line "big" data process and exchange;

- a new technological platform was created based on the technologies of the "microcosm" and biological systems with elements of artificial intelligence;

- the mass consumer has real possibilities for "personalization" of its requests, and the technological platform is able to satisfy them.

Such structural transformation can be probably achieved by creating a new industrial base that will connect the Internet of Things, smart factories and digital infrastructure. At the level of separate firms and companies, technological and industrial trends are forming, which determine the future nature of system development as a whole.

It is obvious that the development of a new industrial base will require significant amounts of capital and costs to maintain human resources. In this regard, a number of issues arises, the solution of which is not only relevant, but is also complex scientific problems. First of all, it is necessary to include the following:

- Study of the fundamentally new nature of the capital accumulation process in the context of individual components (human, intellectual and physical), in conditions when new revolutionary technologies and innovations become the dominant and driving force affecting economic development in the first half of the 21 st century;

- Assessment of changes in the employment market caused by the widespread use of new intelligent computers and global computer networks that create the conditions for both free job search and partial replacement of human knowledge with machine intelligence;

- Justification of the mechanisms of protection against the intensification of social polarization and growth of economic inequality under conditions of potentially high replacement of human labor with machines and intellectual systems, which leads to the development of regulatory measures to ensure a conflict-free transition to a new industrial base;

- The role of a new industrial base in changing the structure of the world economy. The emergence and development of the Industry 4.0, new products and sales markets will result in changing the structure of employment in the leading countries that means a change in the system of the already established international division of labor.

The process of technological and industrial transformation that has already begun will inevitably lead to the transformation of social and economic systems, and here the key problem will not only be the provision of a new quality of economic growth, but also the solution of the employment problem interfacing a new technological platform, the information and social infrastructure of society.

\section{References}

1. L. H. Summers, U.S. Economic Prospects: Secular Stagnation, Hysteresis, and the Zero Lower Bound, Business Economics, 49(2), 65-73 (2014)

2. A. Ando, D. Christelis, T. Miyagawa, Inefficiency of Corporate Investment and Distortion of Savings Behavior in Japan, NBER Working Paper,9444 (2003)

3. F. Hayashi, The Over-Investment Hypothesis, in Lawrence R. Klein, ed., Long-Run Growth and Short-Run Stabilization: Essays in Memory of Albert Ando, Edward Elgar (2006)

4. G. Benigno, L. Fornaro, Stagnation Traps, IMF Conference on Secular Stagnation, Growth, and Real Interest Rate held at Florence (2015)

5. H. Chun, T. Miyagawa, H. K. Pyo, M. Takizawa, K. Tonogi, Declining Rate of Return on Capital and the Role of Intangibles in Japan and Korea, The Fourth World KLEMS Conference Asia KLEMS session (2016) 
6. H. Kagermann, W. Wahlster, J. Helbig, Recommendations for implementing the strategic initiative INDUSTRIE 4.0., Industrie 4.0. WorkingGroup (2013)

7. P. C. Evans, M. Annunziata, Industrial Internet: Pushing the Boundaries of Minds and Machines (2012)

8. M. Swan, Sensor Mania! The Internet of Things, Wearable Computing, Objective Metrics, and the Quantified Self 2.0., J. Sens. Actuator Netw., 1, 217-253 (2012)

9. S. J. Russel, P. Norvig, Artificial Intelligence: A Modern Approach (2nd ed.), Prentice Hall (2003)

10. K. Schwab The Fourth Industrial Revolution: what it means, how to respond,World Economic Forum (2016)

11. E. Brynjolfsson, A. McAfee. The Second Machine Age: Work, Progress and Prosperity in a Time of Brilliant Technologies, W.W. Norton \& Company (2014)

12. D. Spencer, Work in and beyond the Second Machine Age: the politics of production and digital technologies. Work, EmploymentandSociety, 31(1), 142-152 (2017)

13. A. Akaev, S. Rumyantseva, A. Sarygulov, V. Sokolov, Structural-cyclic processes of economic dynamics, 462 (2016)

14. D. Kleinbard, The $\$ 1.7$ trillion dot.com lesson, CNN Money (2000)

15. K. Shiba Central Banks' New Approach to AI: New Settlement System Applying Blockchain Technology and Issuance of Digital Currency. Institute for InternationalMonetaryAffairs (IIMA). Newsletter,3,(2017)

16. J. Ogawa, Global AI startup financing hit \$5bn in 2016, Nikkei Asia Review (2017)

17. J. Lin, Technological Adaptation, Cities, and New Work, Review of Economics and Statistics, 93(2), 554-574 (2011)

18. C. B. Frey, M. A. Osborne, the Future of Employment: How Susceptible are Jobs to Computerization? (2013)

19. C. Brzeski, I. Burk, Die Roboterkommen. Folgen der Automatisierungfür den deutschenArbeitsmarkt, Economic Research (2015)

20. J. Bowles, The computerisation of European jobs, Bruegel (2014)

21. D. Acemoglu, P. Restrepo,Robots and Jobs: Evidence from US Labor Markets (2017)

22. M. Matsaganis, E. Özdemir, T. Ward, A. Zavakou, Non-standard employment and access to social security benefits (2016)

23. S. G. Benzell, L. J Kotlikoff,G. LaGarda, J. D. Sachs, Robots Are Us: Some Economics of Human Replacement, Boston University, Columbia University (2015)

24. ManufacturingtheFuture: The next era of Global Growth and Innovations, McKinsey Global Institute (2012)

25. Disruptive technologies: Advances that will transform life, business, and the global economy McKinsey Global Institute (2013)

26. Poorer Than Their Parents? Flat of Falling Incomes in Advanced Economies, McKinsey Global Institute (2016)

27. A Future That Works: Automation, Employment, and Productivity, McKinsey Global Institute (2012)

28. G. Valenduc, P. Vendramin. Work in the digital economy: sorting the old from the new, ETUI Working paper (2016)

29. C. Degryse. Digitalisation of the Economy and its impact on Labor Markets, ETUI Working paper (2016)

30. E. Jacobs. What Do Trends in Economic Inequality Imply for Innovation and Entrepreneurship?, Washington Center for Equitable Growth (2016)

31. C. M. Mody, Responsible Innovation, Washington Center for Equitable Growth (2016)

32. The Fourth Industrial Revolution: what it means, how to respond, World Economic Forum (2016) 
33. Realizing Human Potential in the Fourth Industrial Revolution An Agenda for Leaders to Shape the Future of Education, Gender and Work, World Economic Forum (2017)

34. The New Economy Beyond the Hype, OECD Report (2001)

35. Future of Work and Skills, OECD Report (2017)

36. IndustrialDevelopment, Report UNIDO (2016)

37. The Role of Technology and Innovation in Inclusive and Sustainable Industrial Development, Report UNIDO (2016)

38. Re-imagining Work. White Paper Work 4.0, German Federal Ministry of Labor and Social Affairs (2016)

39. The Digital Economy of the Russian Federation, Government Report (2017)

40. Digital Economy: Global Trends and Practice of Russian Business, Moscow, HSE (2017)

41. T. Devezas, J. Leitão, A. Sarygulov A., Industry 4.0 - Entrepreneurship and Structural Change in the New Digital Landscape (Springer International Publishing, Cham, 2017) 